\title{
Interactive Tools for the Preservation, Dissemination and Study of Silk Heritage-An Introduction to the SILKNOW Project
}

\author{
Cristina Portalés ${ }^{1, *(\mathbb{D})}$, Jorge Sebastián ${ }^{2}$, Ester Alba ${ }^{2}$ (i) , Javier Sevilla $^{1}$, Mar Gaitán ${ }^{2}$, Paz Ruiz ${ }^{3}$ \\ and Marcos Fernández ${ }^{1}$ \\ 1 Institute of Robotics and Information and Communication Technologies (IRTIC), Universitat de València, \\ 46980 València, Spain; javier.sevilla@uv.es (J.S.); marcos.fernandez@uv.es (M.F.) \\ 2 Department of Art History, Universitat de València, 46010 València, Spain; jorge.sebastian@uv.es (J.S.); \\ ealba@uv.es (E.A.); maria.mar.gaitan@uv.es (M.G.) \\ 3 International R\&D and Innovation Unit of the Research \& Innovation Service, Universitat de València, \\ 46010 València, Spain; paz.ruiz@uv.es \\ * Correspondence: cristina.portales@uv.es; Tel.: +34-963-543-557
}

Received: 19 April 2018; Accepted: 13 May 2018; Published: 15 May 2018

\begin{abstract}
Silk was a major factor for progress in Europe, mostly along the Western Silk Road's network of production and market centers. The silk trade also allowed for the exchange of ideas and innovations, having impacts at economic, technical, functional, cultural and symbolic levels. However, silk has today become a seriously endangered heritage. Although many European specialized museums are devoted to its preservation, they usually lack the size and resources to take advantage of state-of-the-art digital technologies. The aim of this paper is twofold; firstly, we introduce SILKNOW, an interdisciplinary project that has been recently funded by the H2020 Programme of the European Union in order to preserve and promote the heritage of silk textiles; secondly, we introduce a set of interactive tools related to the project.
\end{abstract}

Keywords: silk heritage; interactive tools; thesaurus; virtual

\section{Cultural Heritage and Digital Technologies: A Mediation Space for Social Challenges}

We live in a time of change where technology and access to information have forever transformed the way we communicate and how we perceive reality. Our life and work patterns have been transformed and so has the way we communicate and relate to each other. Our current conception of cultural heritage $(\mathrm{CH})$ has considerably changed, and it is not surprising that it continues to do so. Our look into the past must include an understanding how works of art and certain historical goods have been valued, gathered and preserved since antiquity, and whether this was for their aesthetic value, or for the value granted by past societies who appreciated their historical uniqueness, aesthetics or rarity. This appreciation formed a collecting culture, but also gave birth to the first conservation standards, both technical and legal. However, it was not until the twentieth century that the current concept of $\mathrm{CH}$ was consolidated in a decisive way. This meant recognition was given to cultural assets as significant evidences of human activity, as either material or intangible testimonies. In short, the recent phenomenon of $\mathrm{CH}$ is associated with a critical reflection on the past that recognizes the historical, artistic or cultural values of a given object and if it has a particular meaning that differentiates it from other types of objects and goods [1].

This generic conceptualization has experienced new ramifications that broadened the values we give to $\mathrm{CH}$. Frequently, during the last century, the value of $\mathrm{CH}$ was associated with what differentiates and forms our identity as historical beings [2]. Today, the question of identity is one of the most 
recognizable values of $\mathrm{CH}$ since it is part of the historical and cultural construction of peoples. However, the issues of identity in the construction of the self/us versus the other/them-so frequently seen in certain armed conflicts-have forced us to reflect on the approach that the formation of identity should include values such as cultural diversity, tolerance, peace or democracy, and, especially, respect for the other and their culture. Thus, within a broader cultural framework, $\mathrm{CH}$ must be understood as a set of cultural goods, as a sum of material and intangible cultural manifestations that a society inherits, interprets, appropriates, enjoys and transmits. It is a reference for identity, a source of inspiration for creativity and sustainability for future projections of individuals and, currently, of the society as a whole, as a dynamic dimension is increasingly projected from social, cultural perspectives, and also that of economic development [3].

Likewise, there is a consensus about the need to reconfigure traditional political and social structures, where the Internet, social media and information and communication technologies (ICT) are playing an important role in the development of a new collective consciousness in an intercommunicated world from a local to global level.

Through social media, citizens have relighted the debate on the common good thanks to new channels of citizen mobilization, awareness and the transfer of collective knowledge. Heritage managers should integrate and understand the different mediation channels in order to guarantee management, conservation and dissemination of $\mathrm{CH}$. Moreover, they should involve themselves in areas such as politics, social and cultural expressions of everyday life, platforms, decisions that shape our environment, joint responses to collective problems, as well as the establishment of networks of mutual support.

Silk is a unique example of heritage where memory, identity, creativity and knowledge can be found in just one piece. Few materials have had such an outstanding impact: economic, technical, functional, cultural and symbolic. From flags to canopies, tapestries to furniture, fans to sword sheathes, wedding gowns to traditional costumes, we can find silk in countless contexts over the last millennia. It is usually linked to the Silk Road that for many centuries connected Asia and Europe, permitting the exchange of precious goods_-not just silk—as well as various techniques, knowledge and religions. Within Europe, that route was later expanded by a network of regions and cities that served as creative, productive and commercial hubs for the textile industry, reaching its peak development in the 18th century. However, it is also a multifaceted, living heritage, as it consists of more than the textile itself. Designers, weavers, painters, sellers and users are involved in it. Moreover, its conservation relies not only on heritage professionals, but also on local communities and different stakeholders.

Nowadays, silk heritage is preserved in numerous institutions-local textile museums in most cases-although sometimes it is also part of decorative arts collections in large international museums. In a context of decreasing economic resources for cultural institutions silk is an endangered heritage, since these institutions usually are small or medium in size and lack resources to develop state-of-the-art digital resources. In fact, institutions have been digitizing their artifacts for decades now, but due to a wide variety of sensing and display devices, the resulting digital data is multimodal and heterogeneous and can be depicted in a variety of different forms. For instance, not only can the visible aspect of artifacts be recorded (as images or videos), so too can their shape (3D), internal structure (tomography), spectral signatures, and more. The digital information about the items in these collections are spread across a large number of websites from medium and small museums, whose data is stored into independent repositories, and is of varying quality and nature and lacks proper tagging. Moreover, these collections are largely inaccessible to broader audiences. Additionally, there is also an associated intangible heritage - artisanal weaving techniques—at risk of disappearing (Figure 1, left). New computational methods and tools can help to tackle these issues and to properly curate this fragile heritage.

ICT provides researchers with powerful tools in order to preserve, analyze and exploit digital information. Laboratories are becoming incubators of products that make use of digital data and interfaces for their operation. $\mathrm{CH}$ is not alien to this situation; every day, new initiatives are 
materializing this symbiosis between ICT and SSH (social sciences and humanities), e.g., [4-6]. Virtual tours can be built to visualize and navigate through $\mathrm{CH}$ sites $[7,8]$; 3D models can be generated in order to document the shape of artifacts [9], and allow a richer interaction experience or even the ability to feel their textures through 3D reproductions [10,11]; augmented representations of $\mathrm{CH}$ has also been explored in recent years [12-14]. On the other hand, the representation of immaterial heritage is also possible with new technologies. Crafts, techniques, rituals and other past events can be simulated and disseminated through interactive videos, virtual worlds and other mixed reality experiences [15-17].

In this regard, the connection between computing and silk textiles is not new. In fact, $19^{\text {th }}$-century Jacquard looms [18] are reported to be the most direct ancestors of modern computers, since a number of punched cards laced together into a continuous sequence controlled their operation (Figure 1, right). Much later, this evolved into computer programming and data entry [19,20]. In a similar fashion, state-of-the-art computing can help to maintain the tangible and intangible heritage related to silk textiles.
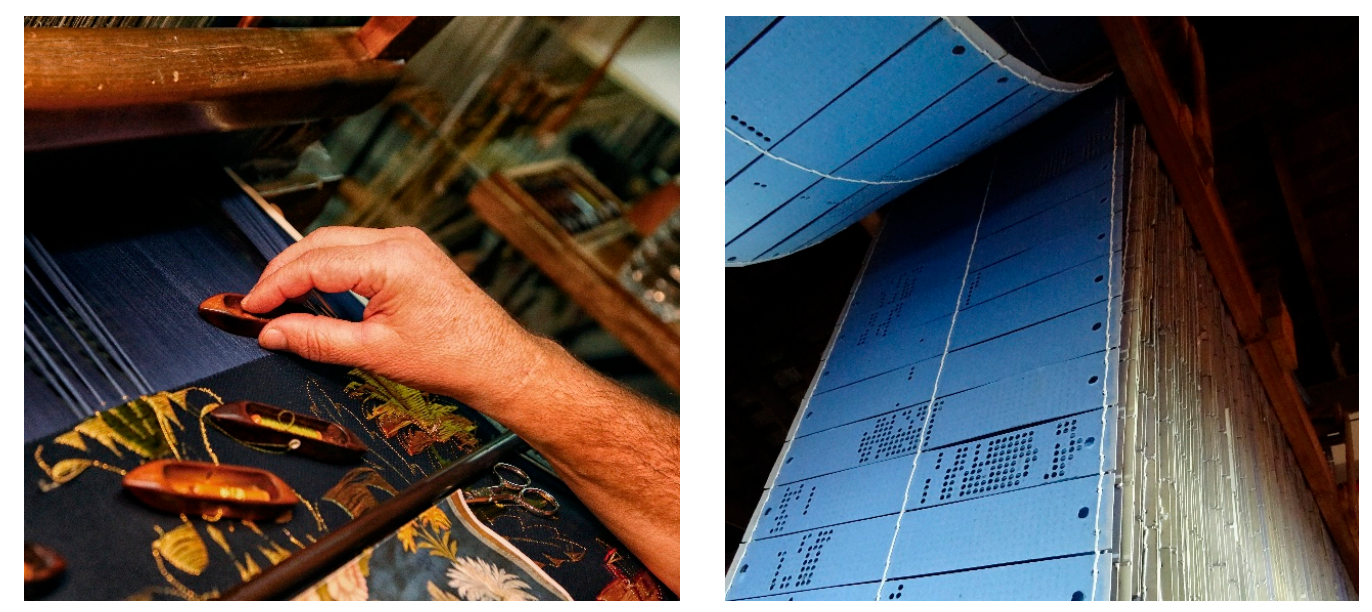

Figure 1. Jacquard looms: an artisan weaving a textile (left); punched cards that embed the textile's drawing (right). Images belong to Garín 1820 S.A. [21].

The potential of information technologies to highlight the value and current needs of silk heritage lies at the core of SILKNOW. This three-year project aims at preserving silk digital heritage and ensuring that it remains accessible to the public, and has been recently funded by the EU's Horizon 2020 Programme under the two-stage call SC6-CULT-COOP-09. It is coordinated by the Universitat de València by means of an interdisciplinary team, formed by the Institute of Robotics and Information and Communication Technologies (IRTIC) and the Faculty of Geography and History. Such collaboration between experts in ICT and SSH is providing traditional humanistic fields with new tools and sets of questions [22]. The partnership comprises of universities, research institutes, an international institution and traditional and high-tech textile SMEs from 6 EU countries, and many different areas, including text analytics, image processing, interactive graphics, semantics, big data, 3D printing, art history, terminology, textile fabrication and conservation. The project will develop its activities between 2018 and 2021.

\section{Aims and Scope}

SILKNOW aims to produce an intelligent computational system that goes beyond current technologies in order to improve our understanding of European silk heritage. Using pre-existent digitized information about this endangered legacy, it will be studied, showcased and preserved through automated digital modeling of its weaving techniques. Users will access the resulting information through visual and tangible simulations, and experience vastly enhanced search tools, providing better results through automatic visual recognition, advanced spatiotemporal visualization, 
multilingual and semantically enriched access to existing digital data. Heritage, educational and tourism institutions will thus benefit from next-generation ICT research, creating synergies open to later applications in creative industries.

The main objectives of the project are:

1. Advanced searching and semantically relating digitized European silk textile heritage, based on data interoperability across different collections. Moreover, we will focus on small to medium size heritage institutions, whose digital data tends to be obsolescent, insufficiently curated and not standardized.

2. Building a "Virtual Loom" to clone ancient weaving techniques. This digital tool will allow users to discover the complexity, artistic and artisanal values of ancient silk textiles and their weaving techniques, while preserving them for future generations.

3. Improvement of the understanding of the European silk heritage. Visual tools that show the spatiotemporal relationships of data will allow users to develop their personal or collective memories, by discovering the many connections that silk textiles can provide to European history.

Figure 2 shows the project objectives in relation to its overall methodology. SILKNOW will take digital silk textiles' data from the databases of several institutions, from offline or online catalogues to APIs (where available). These data will be analyzed and processed with advanced text analytics and image-based deep learning techniques in order to homogenize their content, automatically retrieve semantic information, complete poorly tagged data, and translate the text into four languages (English, French, Italian and Spanish). An ontology will be created to structure the analyzed information. This data will be stored in a web server, which can be accessed and queried by a web-based thesaurus. On the other hand, manufacturing information will be modeled in order to build the "Virtual Loom", whose computational model will be stored in the ontology web server. The outputs of the system will be in form of text, images and 3D models. Additionally, the outputs of queries will be depicted on a dynamic map layer that accounts for their spatial and temporal dimensions, showing representations of the Western Silk Roads.

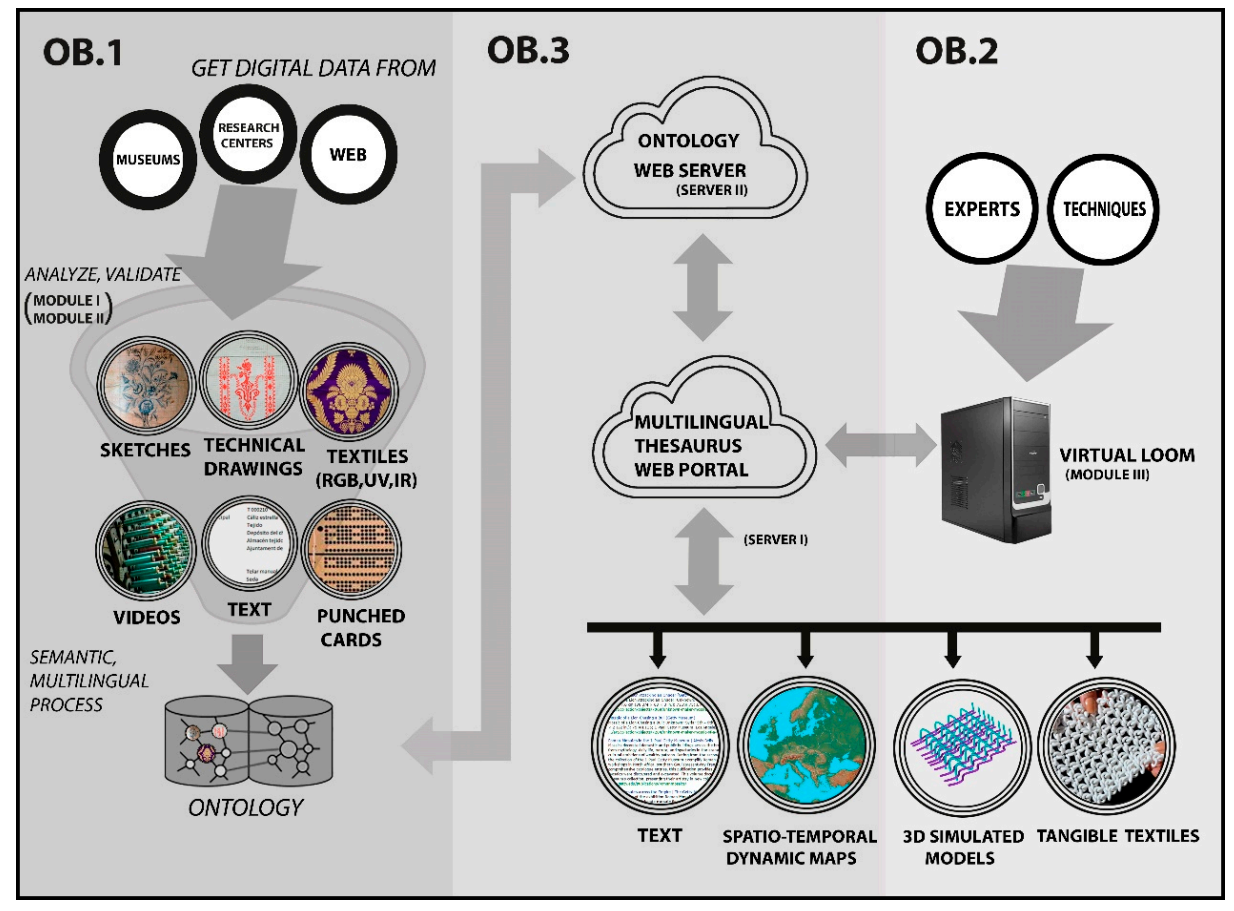

Figure 2. Overview of SILKNOW. The different background grey scales are related to the different objectives of the project (named OB.\#). 


\section{Input Data}

In SILKNOW we will deal with a variety of input data related to historical silk textiles, in order to process them and derive a set of outcomes. Therefore, the system will be able to deal with heterogeneous (regarding to the various ways of discretizing and storing data), multilingual (English, Spanish, French and Italian) and multimodal (text, videos and images of different nature) data, gathered from various collections throughout Europe, and processed in order to ensure interoperability. In Figure 3 a few examples of input data are shown.
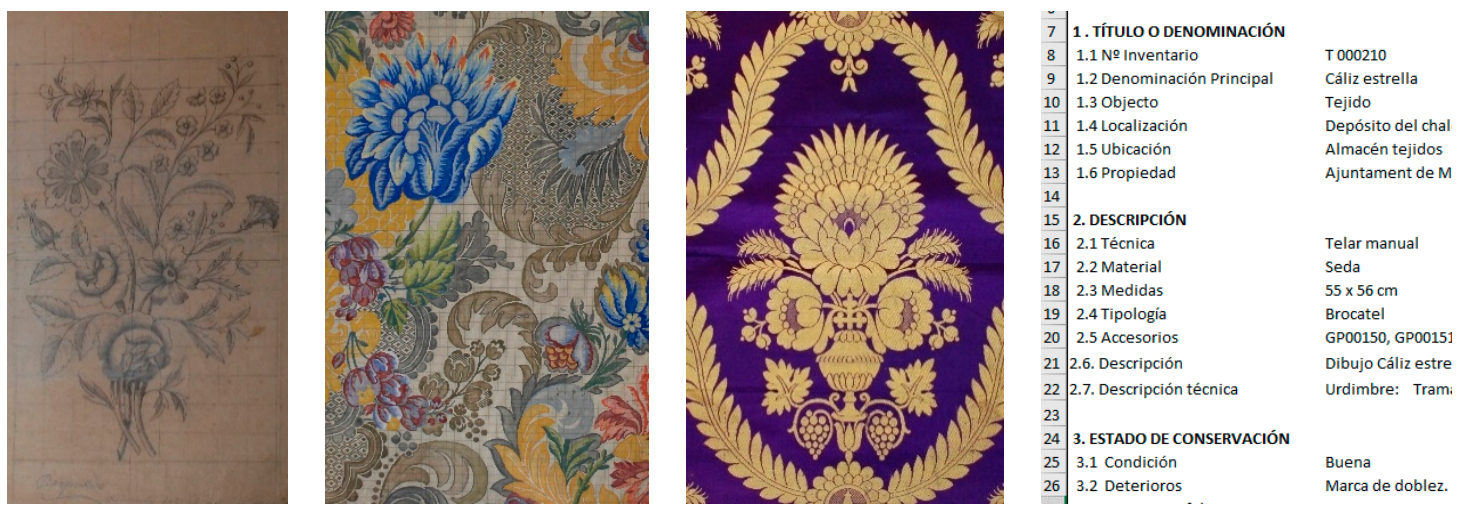

Figure 3. Examples of types of input data considered for the project. Images from left to right: a sketch; a technical drawing; a silk textile; and text associated with an image. Images belong to Garín 1820 S.A. [21].

SILKNOW will ensure that data, heterogeneous in origin, format, tagging, storage systems, etc., can be accessed and related to at the level of semantics, geo-spatial visualization and interaction. Content partners and collaborating institutions will submit digital data of their holdings related to silk textiles, produced within Europe between the 15th and 19th centuries. This data will be diverse in scope and rich in information, including full cataloguing records, photographs, infrared and X-ray images, plus any other technical documentation, in textual or audio-visual format. In parallel, the project's ICT partners will define the tools, scenarios and online platforms that will be used to deliver content to users, based on the requirements provided by the content partners: namely, what kinds of tools and interfaces they would expect to have, for their own use, and also for the use of other foreseeable audiences. Content partners will also undertake validation and quality control analysis of results provided by the computational system.

The collected data will be stored in a repository that will be linked to other repositories, and firstly, to Europeana [23]. We will also build an API to allow prospective data providers to submit their data into our repository, in such a way that the repository can be fed even after the project ends.

\section{Outcomes of the Project}

The project aims to produce a set of relevant outcomes that will arise after the first year of the project for a variety of targeted end users, including humanities researches, ICT experts, educational and creative industries, and other interested public. Some of these outcomes will make use of multimodal and/or interactive solutions, which are described in the following sub-sections.

\subsection{Web Portal with a Multilingual Thesaurus}

Conservation of cultural heritage includes a set of direct and indirect actions in order to ensure the physical persistence of objects, to extend their life cycle and to preserve them in good conditions. However, it is not possible to conceive any conservation action if it is not based on prior knowledge. The registration of a cultural asset in an inventory or its inclusion in a catalog assumes its recognition 
as an element that requires its conservation and protection. Nowadays, museums around the world are generating tools that allow the development of a systematic and coherent cataloging of museum collections and the improvement of a standardized model, in order to avoid the lack of common criteria when dealing with these kinds of records. Therefore, a standardized, unified and organized terminology of the technical vocabularies of cultural assets is one of the most important challenges (especially through ontologies and thesauri). There is also a need to approach these thesauri from a multilingual perspective as it would allow local realities to be accessed from a global angle [24].

SILKNOW will build a web portal that allows the advanced search and representation of information related to silk textile heritage. The need for an integrated, open-architecture, multilingual resource has already been indicated in professional conferences $[25,26]$. A domain knowledge base (i.e., ontology and thesaurus) will be built from the data sources collected in the project, using a combination of extractors from structured and unstructured data tailored to data sources. The ontologies will be based on CIDOC-CRM [27] as a general framework. The Getty Art and Architecture Thesaurus [28] will provide the foundation for an expanded and multilingual thesaurus, devoted to the specific vocabulary of historical silk textiles, that will also include local variations of terms. Based on the domain knowledge base, we will build a specialized cross-lingual semantic annotation engine for silk fabrics and their production. The web portal will be fed with a database containing the digital collections of a variety of institutions that will join the project, some of them having already shown their interests. In this way, users will be able to make complex searches related to silk textiles on a huge database with semantically related information.

As the data of different collections is heterogeneous and many lack of a complete description, the web portal will allow the completion of poorly-tagged images by means of an artificial intelligence engine. In that regard, we will develop new methods for the automatic semantic classification of images showing silk textiles, drawings and sketches (e.g., Figure 3). The set of target variables to be predicted by the classifier will be defined by experts in SSH in collaboration with experts in ICT. In order to train a new model, well-tagged samples from collections will be used. For each new image presented to the software, the target variables will be predicted automatically and with high accuracy; in this way, the predictions can be used to complete the annotations of such images in databases.

Additionally, we will also develop new image-based techniques for assessing the similarity of images showing silk fabrics in such a way that, for a new image supplied to the computational tool, the system will show others with similar characteristics. In this way, we aim to correlate different collections that currently are unconnected.

\subsection{Spatio-Temporal Visualization}

Silk textile heritage involves a series of objects related to space (geographic location) and time. These objects are actually connected; for instance, objects that can be geographically distant might have similar characteristics (fabrics, styles, motives, etc.). The way time-varying, heterogeneous data can be visualized to be meaningful is an open research line. For instance, Ni et al. have addressed the problem of visualizing both movement and contact data in relation to mobile phones [29]. They propose a spatiotemporal flow map layout to visualize when and where people from different locations move into the same places and make contact. Meyer et al. presented a web information system to manage all types of documentary data related to an archaeological site or monument (e.g., text, drawing, elevation, section, photo, etc.) [30]. The system allows users to do different kinds of spatiotemporal searches on the data, especially in 3D.

In SILKNOW, highly interactive graphs will be produced in order to represent the data related to silk textiles according to their spatiotemporal dimensions. Through the web portal, the results of users' searches will be graphically shown, considering both the spatial and temporal dimensions of the related data. As an underlying layer, a geographical map will be shown and, on top of that, interactive graphs will represent the semantic relationships of the search results. Users will also be able to navigate through different periods of time, so they can see the timely evolution of their search. 
For instance, it might happen that a given drawing of the $16^{\text {th }}$ century is found in textiles of other centuries, as fashion has temporal cycles. With these graphics we intend to relate different data in order to evidence connections among styles, drawings, techniques, etc. In this way, users will be able to build a mental map of the search, retrieving more information than he/she intended to collect. As mentioned above, silk has been a historical vector of cultural exchanges that took place through global trade routes. In this context, SILKNOW will provide the best visualization of the Western Silk Roads so far.

Queries to the multilingual thesaurus will return results shown on a spatial-temporal representation. This visualization is the result of the representation of a fragment of the ontology data, related to the visualization ontologies field. This field has a constant activity that proves that this topic is of interest today and it may evolve in the near future [31]. In SILKNOW a natural language-based intelligent silk $\mathrm{CH}$ searcher will be created. This tool will guide the user by the use of a recommender system that he/she can interact with through different, rich and highly interactive user interfaces.

\subsection{Cloning and Tangible Reproductions of Historical Textiles}

Textile heritage is particularly fragile, and not only because of its material condition. The perception of cultural goods experiences transformations that have influenced its permanence and conservation, or even resulted in their destruction or alteration. From a historical perspective, understanding the notion of $\mathrm{CH}$, its significance, and its values are decisive for research on not only the inherited but also on the lost, as it allows an appreciation of how these values were maintained, destroyed or mutated, based on the social, political and economic criteria that are associated with a historical, artistic or cultural good [32].

This consideration understands heritage as something linked not so much to identity, but as something closer to the notion of preservation and lost memory. Undoubtedly, analysis of these meanings allows us to draw the lines that have marked, during historical evolution, the decisions that have weighed on its conservation, on the modification or reconstruction of its uses and functions, on its destruction or on the aesthetic evaluations—-formal, stylistic or symbolic —in time [33].

In this context, the reproduction or reconstruction of textile pieces by digital, automated means, can open up an entirely new approach to this fragile heritage. Recently, some attempts have been made in order to deal with the internal structure of textiles from different perspectives. For instance, in $[34,35]$ the WiseTex software is introduced, which implements a generalized description of the internal structure of textile reinforcements on the unit cell level, which can subsequently be 3D-modeled. Differently, in [36] a procedure for the automatic classification of woven fabric structure in the textile industry is given, which is based on a neural network classifier that works on images of the fabrics. However, ancient textiles are more difficult to reproduce because they embed more complex structures, specific styles or even ornamental additions not included in the original designs. Jacquard looms allowed the creation of silk textiles characterized with complex woven in-designs. Fabrics made with these looms include styles such as brocade, damask and brocatelle.

In SILKNOW we will preserve the fragile ancient art of weaving by directly "cloning" the way it was woven by means of a Virtual Loom software module. This module will be accessible through the web portal and as an independent application. By means of this tool, high resolution 3D models of the textiles will be produced from images. These models will be graphically accessible and will be materialized by means of 3D printing technology.

Within this module, we will make use of the semantic information attached to a given image, as derived by the text analytics and image modules. Having information about the weaving technique (to which mathematical models will be defined) and the image itself (mainly, technical drawings) corrected for possible imperfections (e.g., perspective, etc.), virtual models of the fabrics will be automatically produced with a virtual reality motor generation-based software, such as Unity [37], that additionally allows the generation of multi-platform solutions. Therefore, 3D virtual models of the textiles and their internal structure will be possible after identification of the weaving technique. 
These models will be available in both visual and tangible forms and will be highly interactive (e.g., users would be able to change the color of threads or "paint" the models with different spectral bands when available).

The produced models with the virtual loom will be printable. Regarding 3D printing technology related to textiles, two techniques exist: (1) 3D printing on fabrics (e.g., [38]); (2) 3D printed clothes (e.g., [39]). The first one consists of printing and attaching 3D shapes to existing fabrics (e.g., silk). The second one consists on printing individual 3D shapes and joining them to form clothes. However, studies are still incipient and none of the techniques are mature enough to allow for the massive fabrication of textiles with 3D printers [38-41]. In SILKNOW we will directly tackle these issues in order to step forward in the R\&D of textile 3D printing technology and its application in innovative textile design processes, which might change the nature of the fashion industry and other related sectors, such as textile manufacturing and commerce.

\subsection{Educational Materials}

Communication between heritage and the social subject has been quite often based on a personal aesthetic experience. This experience usually involves understanding the highly communicative potential of artistic works, that are capable of generating multiple emotions in specific individuals [42]. However, as Berger says, art-in short, and by extension, the cultural good-by itself does not possess communicative power to transmit ideas or values from an educational point of view. $\mathrm{CH}$ and the elements that define it do not have the power to transform society on their own, but rather the individual, or the collective that contemplates, apprehends, gets excited, assimilates, knows, educates or enjoys it, is able to carry out a critical process of social improvement. Art and heritage have in common that they stimulate emotional communication about ideas, expressions of daily life, reflections, etc.; in sum, everything that supposes an emotional catalyst from the present to the past and in a certain way, lays the foundations for the construction of the pillars of the future [43].

Thus, heritage from an integral point of view becomes a visible element in public spaces and in conservation institutions, visibility that together with its strong communicative power and through a correct pedagogical mediation is capable of reaching a wide social spectrum. For Simmel [44], cultural goods have a strong socializing force that establishes interesting points of union on a ludic dimension and social enjoyment. This offers a new perspective on heritage that goes through social and collective involvement and different channels of social participation.

Accordingly, educational materials about silk heritage will be produced within SILKNOW, in order to disseminate the results of the project to wider audiences lacking expertise in silk heritage, who therefore require a guided learning process. These materials will be based on both input data and output results of the project and will be interactive. Teaching units in digital format will be organized according to different levels of the Common European Framework of Reference for Languages, to be used at Instituto Cervantes' teaching schools worldwide, disseminating this important heritage globally.

Moreover, a number of formative and didactic activities with European design schools will help to promote $\mathrm{CH}$ as the base for improving and creating new jobs in the creative industries sector. These projects will introduce future professionals to the employment environment, associated with innovation and based on $\mathrm{CH}$, thus bringing the past into the future.

\section{Conclusions}

Culture is no longer a mere reflection of a society, and must be seen and understood as an active principle that generates, constitutes, shapes and makes ideas evolve. The communicative capacity of $\mathrm{CH}$ empowers the mediation of heritage professionals, enabling them to make better use-more collective, demanding and participatory—of digital technologies. The narrative ability of heritage as a medium to transmit ideas, experiences, images and emotions, makes it a perfect tool that helps to understand and assimilate concepts [45]. 
Consequently, SILKNOW aims to improve the understanding of silk textiles heritage and its rich diversity, applying next-generation ICT research to the needs of various users (museums, education, tourism, creative industries, and media), and preserving an intangible heritage (ancient weaving techniques) for younger generations. Its research activities and outputs will make use of multimodal and interactive solutions which will have direct impact in computer science and data management, focusing on searching digital content in heterogeneous, multilingual and multimodal databases and displaying the processed information in a variety of forms. We will release the digital data about silk heritage into the public domain, making digital silk heritage content available for creating value, facilitating new business opportunities and novel concepts, and therefore providing opportunities for new creative projects in different sectors.

Its results should foster perceiving $\mathrm{CH}$ as an integral reality-with emphasis on institutions or society to promote participation, sharing of knowledge or education-in the appreciation of culture. The project started its research activities on 1 April 2018, and will be progressively monitored and evaluated by the European Commission according to the approved technical working plan. Additionally, the established impact indicators will be reviewed along the project's lifespan to assess for the dissemination and exploitation of activities, as well as its open access policy. Understanding heritage as an integral reality requires a collective perception and the establishment of cultural networks that are able to combine monuments, archaeological sites, museums, natural landscapes, cultural landscapes, ethnographic realities, historical sites, collective memory, citizen appreciation, with the dimensions of social, cultural and educational realities in a single interconnected universe. The road is open, all we need now is to begin to travel.

Author Contributions: All authors contributed equally to the paper.

Acknowledgments: The research leading to these results is in the frame of the "SILKNOW. Silk heritage in the Knowledge Society: from punched cards to big data, deep learning and visual/tangible simulations" project, which has received funding from the European Union's Horizon 2020 research and innovation program under grant agreement No. 769504.

Conflicts of Interest: The authors declare no conflict of interest.

\section{References}

1. Arpin, R. Notre patrimoine, un présent du passé. Documentation et Bibliothèques 2000, 47, 3-45.

2. Del Monte, M.M. Museo y patrimonio. Del objeto a la planificación estratégica. In Museos. es: Revista de la Subdirección General de Museos Estatales; Ministerio de Educación, Cultura y Deporte: Madrid, Spain, 2007; pp. 16-29.

3. Ariño Villarroya, A. El rostro cambiante de la cultura: Para una definición sociológica. In Ensayos de Filosofía de la Cultura; Biblioteca Nueva: Madrid, Spain, 2002; pp. 239-256.

4. ARCHNET. Available online: https:/ / archnet.org/ (accessed on 14 May 2018).

5. ARTECHNE. Technique in the Arts, 1500-1950. Available online: https://artechne.wp.hum.uu.nl/ (accessed on 14 May 2018).

6. Granero-Montagud, L.; Portalés, C.; Pastor-Carbonell, B.; Ribes-Gómez, E.; Gutiérrez-Lucas, A.; Tornari, V.; Papadakis, V.; Groves, R.M.; Sirmacek, B.; Bonazza, A.; et al. Syddarta: New methodology for digitization of deterioration estimation in paintings. In Proceedings of the SPIE-Optics for Arts, Architecture, and Archaeology IV, Munich, Germany, 15-16 May 2013; pp. 879011:1-879011:19.

7. Lerma García, J.L.; Vidal, J.; Portalés Ricart, C. Three-dimensional city model visualisation for real-time guided museum tours. Photogramm. Rec. 2004, 19, 360-374. [CrossRef]

8. Napolitano, R.K.; Scherer, G.; Glisic, B. Virtual tours and informational modeling for conservation of cultural heritage sites. J. Cult. Heritage 2017, 29, 123-129. [CrossRef]

9. Navarro, S.; Seguí, A.E.; Portalés, C.; Lerma, J.L.; Akasheh, T.; Haddad, N. Integration of tls data and non-metric imagery to improve photo models and recording-A case study on djin block no. 9, petra (jordan). In Proceedings of the 15th International Conference on Virtual Systems and Multimedia, Vienna, Austria, 9-12 September 2009; pp. 58-63. 
10. Neumüller, M.; Reichinger, A.; Rist, F.; Kern, C. 3D printing for cultural heritage: Preservation, accessibility, research and education. In 3D Research Challenges in Cultural Heritage; Springer International Publishing AG: Basel, Switzerland, 2014; pp. 119-134.

11. Themistocleous, K.; Ioannides, M.; Agapiou, A.; Hadjimitsis, D.G. The methodology of documenting cultural heritage sites using photogrammetry, uav, and 3D printing techniques: The case study of asinou church in cyprus. In Proceedings of the Third International Conference on Remote Sensing and Geoinformation of the Environment (RSCy2015), Paphos, Cyprus, 16-19 March 2015; p. 953510.

12. Portalés, C.; Lerma, J.L.; Pérez, C. Photogrammetry and augmented reality for cultural heritage applications. Photogramm. Rec. 2009, 24, 316-331. [CrossRef]

13. Portalés, C.; Alonso-Monasterio, P.; Viñals, M.J. 3D virtual reconstruction and visualisation of the archaeological site castellet de bernabé (Llíria, Spain). Virtual Archaeol. Rev. 2017, 8, 75-82. [CrossRef]

14. Tscheu, F.; Buhalis, D. Augmented reality at cultural heritage sites. In Information and Communication Technologies in Tourism 2016; Springer International Publishing AG: Basel, Switzerland, 2016; pp. 607-619.

15. Yang, C.; Peng, D.; Sun, S. Creating a virtual activity for the intangible culture heritage. In Proceedings of the 16th International Conference on Artificial Reality and Telexistence-Workshops (ICAT'06), Hangzhou, China, 29 November-1 December 2006; pp. 636-641.

16. Giaccardi, E. Collective storytelling and social creativity in the virtual museum: A case study. Des. Issues 2006, 22, 29-41. [CrossRef]

17. Carrozzino, M.; Scucces, A.; Leonardi, R.; Evangelista, C.; Bergamasco, M. Virtually preserving the intangible heritage of artistic handicraft. J. Cult. Heritage 2011, 12, 82-87. [CrossRef]

18. Anderson, D.; Delve, J. Joseph marie jacquard: Inventor of the jacquard loom. IEEE Ann. Hist. Comput. 2007, 29, 90-102. [CrossRef]

19. Essinger, J. Jacquard's Web: How a Hand-Loom Led to the Birth of the Information Age; Oxford University Press: Oxford, UK, 2004.

20. Teaching Palette. Jacquard Loom: Early Computer Programing. Available online: https:/ /www.youtube. com/watch?v=lwozgRPLVC8 (accessed on 14 May 2018).

21. Espolines de garín 1820. Available online: http:/ / garin1820.com/ (accessed on 10 April 2018).

22. Sebastián Lozano, J. Digital Art History at the Crossroads; Humboldt-Universität zu Berlin: Berlin, Germany, 2017.

23. Europeana Fashion. Available online: http://www.europeana.eu/portal/es/collections/fashion (accessed on 14 May 2018).

24. Alba Pagán, E. Catálogo e inventario como instrumentos para la gestión del patrimonio cultural. In Educación y Entorno Territorial de la Universitat de València; López, R., Ed.; Universitat de Valènci: València, Spain, 2014; pp. 67-93.

25. Haffner, D. A textile thesaurus-Merging and enlarging the existing vocabularies. In Proceedings of the ICOM General Conference, Milan, Italy, 3-9 July 2016.

26. Gunzburger, C. The Textile Museum Thesaurus; Textile Museum: Washington, DC, USA, 2005.

27. Cidoc-crm. Conceptual Reference Model. Available online: http://www.cidoc-crm.org/ (accessed on 14 April 2018).

28. The J. Paul Getty Trust. The Getty Research Institute. Art \& Architecture Thesaurus Online. Available online: http:/ / www.getty.edu/research/tools/vocabularies/aat/ (accessed on 14 April 2018).

29. Ni, B.; Shen, Q.; Xu, J.; Qu, H. Spatio-temporal flow maps for visualizing movement and contact patterns. Visual Inform. 2017, 1, 57-64. [CrossRef]

30. Meyer, É.; Grussenmeyer, P.; Perrin, J.-P.; Durand, A.; Drap, P. A web information system for the management and the dissemination of cultural heritage data. J. Cult. Heritage 2007, 8, 396-411. [CrossRef]

31. Lantow, B.; Mikhailov, S.; Petrov, M. Ontology visualization: A systematic literature analysis. In Proceedings of the BIR Workshops, Prague, Czech Republic, 14-16 September 2016.

32. Desvallées, A.; Mairesse, F. Conceptos Claves de Museología; Armand Colin: París, France, 2010.

33. Arciniega García, L. Excéntricas aproximaciones historiográficas hacia el patrimonio cultural. In Segona trobada Universitat de València-Instituts d'Estudis Comarcals: Aportacions per a la Reflexió al Voltant del Territori, 2012; Servei de Publicacions: Barcelona, Spain, 2012; pp. 103-120.

34. Lomov, S.V. Modelling the geometry of textile composite reinforcements: Wisetex. In Composite Reinforcements for Optimum Performance; Boisse, P., Ed.; Woodhead Publishing: Sawston, Cambridge, UK, 2011; pp. 200-238. 
35. Verpoest, I.; Lomov, S.V. Virtual textile composites software wisetex: Integration with micro-mechanical, permeability and structural analysis. Compos. Sci. Technol. 2005, 65, 2563-2574. [CrossRef]

36. Jing, J.; Wang, J.; Li, P.; Li, Y. Automatic classification of woven fabric structure by using learning vector quantization. Procedia Eng. 2011, 15, 5005-5009. [CrossRef]

37. Unity 3D. Available online: https:// unity3d.com/es (accessed on 14 May 2018).

38. Sabantina, L.; Kinzel, F.; Ehrmann, A.; Finsterbusch, K. Combining 3D printed forms with textile structures-Mechanical and geometrical properties of multi-material systems. IOP Conf. Ser.: Mater. Sci. Eng. 2015, 87, 012005. [CrossRef]

39. Melnikova, R.; Ehrmann, A.; Finsterbusch, K. 3D printing of textile-based structures by fused deposition modelling (fdm) with different polymer materials. IOP Conf. Ser.: Mater. Sci. Eng. 2014, 62, 012018. [CrossRef]

40. Pei, E.; Shen, J.; Watling, J. Direct 3D printing of polymers onto textiles: Experimental studies and applications. Rapid Prototyp. J. 2015, 21, 556-571. [CrossRef]

41. Rivera, M.L.; Moukperian, M.; Ashbrook, D.; Mankoff, J.; Hudson, S.E. Stretching the bounds of 3D printing with embedded textiles. In Proceedings of the 2017 CHI Conference on Human Factors in Computing Systems, Denver, CO, USA, 6-11 May 2017; pp. 497-508.

42. Mateos Rusillo, S.M. Hacia una comunicación global del patrimonio cultural, o cómo potenciar su uso fomentando su preservación. In La Comunicación Global del Patrimonio Cultural; Trea: Gijón, Spain, 2008; pp. 19-52.

43. Tugores, F.; Planas Ferrer, R. Introducción al Patrimonio Cultural; Ediciones Trea: Gijón, Spain, 2006.

44. Simmel, G. The Sociology of Georg Simmel: Translated ed., and with an Introduction by kurt h. Wolff; The Free Press: Glencoe, IL, USA, 1950.

45. Habermas, J. Teoría de la Acción Comunicativa; Taurus: Madrid, Spain, 1981.

(C) 2018 by the authors. Licensee MDPI, Basel, Switzerland. This article is an open access article distributed under the terms and conditions of the Creative Commons Attribution (CC BY) license (http:/ / creativecommons.org/licenses/by/4.0/). 